\title{
Eine griechische Tragödie
}

\section{Samia Hurst}

Prof. Dr. med., Institut für Bioethik (iEH2), Medizinische Fakultät, Genf

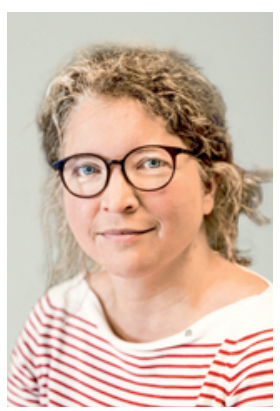

Heute erzähle ich Ihnen eine Tragödie. Eine Geschichte, in der Menschen leiden und als Spielball von Mächten agieren, derer sie nicht Herr werden. Das 21. Jahrhundert setzt seine Zeichen - bei den hier wirkenden Mächten handelt es sich nicht um launische Götter oder die Macht des Schicksals, sondern vielmehr um die des Marktes und der Wirtschaft.

Erster Akt: Im Dezember 2016 wird die griechische Novartis-Tochter der Korruption auf breiter Ebene beschuldigt. Konkret wird ihr vorgeworfen, die Preise für bestimmte Krebsmedikamente künstlich hoch zu halten. Ein Mitarbeiter des vorgeladenen Managements unternimmt einen Selbstmordversuch. Er erklärt sein Handeln damit, dass er nicht zum Sündenbock gemacht werden wolle [1]. Die Novartis-Mutter beruft sich darauf, dass sich das Unternehmen «in allen Geschäftsbereichen höchsten Standards in Sachen Geschäftsethik und Regelkonformität verpflichtet fühlt und allfällige Vorwürfe zu fragwürdigen Handelspraktiken sehr ernst nimmt». Novartis sagt der Justiz volle Unterstützung zu.

Zweiter Akt: Novartis wird hier nicht zum ersten Mal der Korruption beschuldigt. In Südkorea ist das Unternehmen seit letztem Sommer Gegenstand von Untersuchungen, in China wurde es mit einer Busse belegt und in den Vereinigten Staaten wurde nach ähnlichen Anschuldigungen eine Vergleichszahlung von 390 Millionen USD ausgehandelt. Jedes Mal wird gleich reagiert: Es handle sich um lokale Vorkommnisse, von denen sich die Unternehmensführung distanziere, und sie erinnert daran, dass die Unternehmensregeln ein solches Handeln untersagen [2]. Novartis sagt der Justiz volle Unterstützung zu.

Dritter Akt: Novartis ist nicht - bei weitem nicht - das einzige Pharmaunternehmen, das in jüngster Vergangenheit beschuldigt oder mit einer Busse belegt wurde [3]. Nach einem im vergangenen Jahr von Transparency International [4] veröffentlichten Bericht scheint dies ein Problem zu sein, das den gesamten Sektor betrifft. Was bedeutet dies nun für die Mitarbeitenden im Pharmasektor? Je stärker sie nach ihren Zahlen bewertet werden, desto mehr werden sie sich versucht sehen, diese zu beeinflussen. Wenn die Konkurrenz völlig ungestraft so handelt, kann dies für den einzelnen Mitarbeitenden ein Dilemma bedeuten. Zweifellos gilt Korruption als schlecht. Sollte sie sich im realen
Arbeitsumfeld des Mitarbeitenden aber als lukrativ erweisen, wird diese Botschaft ebenfalls voll $\mathrm{zu}$ ihm durchdringen. Wenn das Unternehmen dann keine konkret abschreckenden Massnahmen ergreift, wird die repetitive verbale Distanzierung vom wiederholten Fehlverhalten immer unglaubwürdiger.

Wenn ein Fall von Korruption in einer lokalen Tochtergesellschaft auftritt, liegt ein Teil der moralischen Verantwortung daher wahrscheinlich sehr wohl bei der Unternehmensleitung. In diesem Fall in der Schweiz. Das verursacht Unbehagen. Das ist unangenehm. Ein Unternehmen steht aber als Ganzes auch immer im Wettbewerb mit anderen. Es kann auch immer wieder feststellen, dass andere auch korrupt sind und davon profitieren. Ein ganzes Unternehmen kann als solches auch vor einem Dilemma stehen.

Im ersten Akt könnten wir daher geneigt sein, Menschen anzuklagen, denen das moralische Rückgrat fehlt. Im zweiten wird das Unternehmen beschuldigt. Im dritten ist allerdings festzustellen, dass es sich bei den Verantwortlichen auch um Staatengefüge handeln kann - also um uns - und um den Markt, also wieder um uns.

Das ist natürlich auch unangenehm. Was müsste geschehen, damit sich die Situation ändert? Die Lösung könnte vielleicht von den Staaten selbst, aber auch aus der Industrie kommen. Anzuerkennen, dass man eine Verantwortung hat, solche Fälle zu verhindern, und harmlose Bussen, durch gezielte Sanktionen zu ersetzen, etwa die Laufzeitverringerung von Patenten: Dies könnte eine Wirkung haben. Was könnten die Unternehmen tun? Im Konkurrenzkampf übernehmen sie Verhaltensmuster, die (gerechtfertigterweise) ihrem Image abträglich sind. Und sie tun dies, weil die anderen es tun. Es ist schwer, allein aus diesem kleinen Teufelskreis auszuscheren. Gemeinsam hingegen wäre dies sehr wohl möglich. Eine glaubwürdige, branchenweite Initiative zum gemeinsamen Kampf gegen die Korruption wäre das nächste Mal eine deutlich bessere Antwort.

\section{Literatur}

1 https://www.rts.ch/info/economie/8282935-une-enquete-pourcorruption-presumee-visant-novartis-en-grece.html

2 https://www.novartis.com/about-us/corporate-responsibility/ doing-business-responsibly/ethics-compliance/anti-briberyanti-corruption

3 Dyer O. Novartis is under investigation for allegedly bribing thousands of Greek doctors. BMJ 2017;356:j130.

4 http://www.transparency.org.uk/publications/corruption-inthe-pharmaceutical-sector/ 